\title{
SUPERVISI DALAM PELATIHAN
}

\section{Studi Kasus di SD Islam Al-Azhar 20 Cibubur}

\author{
Inda Fitriani Effendi*
}

\begin{abstract}
this research aims to understand about: (1) training process. training based on supervision is one way to monitor teaching improvement as well as the teachers. The process of training start from planning, analyse, assessment, training and development, program content, learning principle, actual program, skill knowledge ability of works, evaluation (2) process supervision trough several steps and the process itself base on colabbotarive, creative and supportive supervision (3) supervision not only held by school but also the trainer from another institution are requested to do supervision in classrooms in order to monitor the learning process. The supervision will be held at the end of training session. (4) Empowering is one way to help teacher to be improved in order to do efective work. Empowering also means to recoqnize the teachers' right and obligation. Teacher who is able to achieve Teaching Knowledge Test, will be put as a teacher model that can help other teachers to be improved.
\end{abstract}

Keywords : training process, supervision and empowering

\section{PENDAHULUAN}

SD Islam Al-Azhar 20 Cibubur menerapkan manajemen peningkatan mutu berbasis sekolah yang merupakan bentuk manajemen yang memberikan otonomi lebih besar kepada pihak sekolah, dan memberikan peluang untuk dapat mengakomodasi keterlibatan semua kalangan, sehingga tercipta partisipasi secara langsung antar warga sekolah yaitu guru, siswa, kepala sekolah, karyawan dan masyarakat. Untuk meningkatkan kualitas sekolah, Kepala Sekolah mengadakan berbagai macam pelatihan yang di supervisi. Pelatihan tersebut menjadi unik karena setiap bentuk pelatihan akan disupervisi langsung oleh narasumber pelatihan. Supervisi tersebut menjadi bagian penting dalam pelatihan untuk mengetahui perkembangan guru setelah mengikuti pelatihan.

Supervisi merupakan sarana untuk mengembangkan perofesionalisme guru dalam rangka pemberdayaan guru. Supervisi bukanlah suatu kegiatan untuk mengawasi pelaksanaan tugas guru atau menilai performasi guru, tetapi merupakan kegiatan yang bertujuan membantu guru dalam melaksanakan tugasnya.

Dalam proses pemberdayaan diusahakan agar orang berani menyuarakan dan mempertimbangkan ketidakseimbangan antara hak dan kewajiban. Pemberdayaan mengutamakan usaha sendiri dari orang yang diberdayakan untuk meraih keberdayaannya.

Mengawali penelitian ini, kemampuan Kepala Sekolah dalam mensiasati dan mengatur strategi pelatihan dalam rangka pemberdayaan guru inilah yang membuat peneliti ingin mengetahui secara mendalam tentang bentuk Supervisi dalam Pelatihan.

\footnotetext{
* Trainer di Lembaga Pelatihan FLASH English
} 
Menurut peneliti langkah-langkah yang diambil oleh Kepala Sekolah dan dukungan penuh dari yayasan merupakan suatu terobosan baru dalam manajemen pendidikan berbasis sekolah.

\section{Pelatihan}

Raymond A. Noe et al (2003:105) menjelaskan pelatihan "training refers to a planned effort to facilitate the learning of job related knowledge skill and behavior by employee". Pelatihan berhubungan dengan usaha yang terencana untuk memfasilitasi pekerja dalam pembelajaran yang berhubungan dengan pengetahuan keterampilan dalam bekerja dan bersikap.

Sallie E. Gordon (1994:2), mendefinisikan pelatihan sebagai berikut, "training on the other hand has mostly consisted of short term activities such as workshop that provide knowledge and skill for immediate use." Definisi ini mengandung makna bahwa pelatihan adalah aktifitas pembelajaran dimana waktu pelaksanaaNnya pendek yang mempelajari pengetahuan atau keterampilan untuk pekerjaan yang sifatnya mendesak.

Selanjutnya, pelatihan merupakan usaha peningkatan mutu peserta pelatihan dalam melaksanakan tugas sehari-hari. Pelatihan merupakan bagian yang tidak dapat dipisahkan dari pendidikan. Artinya, kalau berbicara mengenai pendidikan maka kita juga sedang berbicara pelatihan.

Pelatihan didefinisikan oleh Ivancevich yang dikutip oleh Sutrisno sebagai usaha untuk meningkatkan kinerja karyawan dalam pekerjaannya sekarang atau dalam pekerjaan lain yang akan dijabatnya segera. Pelatihan terkait dengan keterampilan dan kemampuan yang diperlukan untuk pekerjaan yang sekarang dilakukan. Pelatihan berorientasi ke masa sekarang dan membantu karyawan untuk menguasai keterampilan dalam pekerjaannya. Lebih lanjut menurut As'ad yang kutip oleh Sutrisno (2011:67), pelatihan menyangkut usaha-usaha yang terencana yang diselenggarakan agar mencapai penguasaan akan keterampilan, pengetahuan dan sikap-sikap yang relevan terhadap pekerjaan.

Pelatihan juga berfungsi untuk meningkatkan kinerja karyawan atau pekerjaan yang saat ini sedang ditangani atau segala sesuatu yang terkait dengan pekerjaan. Untuk membuatnya lebih efektif, pelatihan harus melibatkan sebuah pengalaman pembelajaran menjadi suatu aktivitas organisasi yang terencana dan dirancang untuk mengenali kebutuhan. Idealnya, pelatihan seharusnya dirancang untuk mencapai tujuan organisasi dan secara bersamaan dapat memenuhi tujuan karyawan secara individual.

Dari beberapa deskripsi konsep di atas maka dapat disintesiskan pelatihan adalah proses pembelajaran atas serangkaian usaha yang terencana untuk mengembangkan keterampilan peserta, menyediakan informasi, dan membentuk sikap agar dapat bekerja secara lebih efektif dan efisien.

\section{Supervisi}

Thomas J Sergeovani (2000:5) mengatakan, "the supervisory functions are so important in helping school contribute effectively to rigorous and outhentic learning". Supervisi berfungsi sangat penting untuk membantu sekolah dalam berkontribusi secara efektif dalam pembelajaran yang autentik dan berkelanjutan. 
Thomas W. Comstac (2000:8) mendefinisikan supervisi sebagai "definition of supervision would be the act of controlling or directing the accomplishment of work. Other might say that is being in charge of people or controlling activities". Definisi dari Supervisi dapat diartikan sebagai kegiatan mengontrol atau mengarahkan pencapaian dari suatu pekerjaan. Atau dapat dikatakan menjadi penanggung jawab terhadap orang-orang atau mengontrol aktivitas.

Edwin C. Leonard (2010: 119) mengatakan bahwa "people are the most important resource that a supervisor is asked to manage. Human beings have values, attitudes, needs and expectations significantly influence their behaviors on the job. The feelings people have toward their supervisor, their job environment, their personal problems, and numerous other factors are often difficult to ascertain impact on employee motivation and work performance. However, they have a tremendous impact on employee motivation and work performance". Manusia adalah sumberdaya terpenting yang dikelola seorang supervisor. Manusia memiliki nilai-nilai, sikap-sikap, kebutuhan-kebutuhan, dan harapan-harapan yang secara signifikan memberi pengaruh pada perilaku mereka dalam bekerja. Perasaan-perasaan yang mereka miliki berpengaruh terhadap hubungan dengan supervisor mereka, lingkungan kerja mereka, problem-problem pribadi mereka dan berbagai faktor-faktor lainnya. Namun demikian hal-hal tersebut berpengaruh besar terhadap motivasi bekera dan kinerjanya.

Supervisi mempunyai pengertian yang luas, berikut adalah beberapa pengertian supervisi menurut para pakar, menurut Nealey dan Evans yang dikutip oleh Ngalim Purwanto ( 2010:76). "the term of supervision is used to describe those activities which are primarily and directly concerned with studying and improving the conditions which surround the learning and growth of pupil and teacher". Istilah supervisi digunakan untuk menggambarkan aktivitas utama dan secara langsung berkaitan dengan pembelajaran dan pengembangan kondisi yang terkait dengan proses pembelajaran dan perkembangan peserta didik dan guru.

Tujuan supervisi pendidikan menurut Made Pidarta (2009:70), yaitu: (1) membantu menciptakan lulusan yang optimal dalam kuantitas dan kualitas; (2) membantu guru mengembangkan pribadi, kompetensi dan sosialnya; (3) membantu kepala sekolah mengembangkan program yang sesuai dengan kondisi maysrakat setempat; (4) ikut meningkatkan kerja sama dengan masyarakat atau komunitas sekolah.

Dari beberapa deskripsi konsep di atas maka dapat disintesiskan bahwa supervisi adalah suatu kegiatan atau usaha yang dilakukan untuk meningkatkan kinerja guru dalam bentuk: melakukan monitoring, memberi bantuan pemecahan masalah, perbaikan kinerja, membangun kerjasama, dan merancang efektifitas kerja.

\section{Pemberdayaan}

T.J. Atchison (1991:127) "empowering means giving employees responsibility and authority to make decision regarding all aspects of product development or customer service." Artinya, Pemberdayaan berarti memberikan karyawan tanggung jawab dan kewenangan untuk membuat suatu keputusan yang berkaitan dengan seluruh aspek terhadap pengembangan produk dan layanan pelanggan

Russel dan Taylor (2003:115) berpendapat bahwa "empowerment is giving workers an authority to alert management problem". Pemberdayaan adalah memberikan wewenang kepada pekerja untuk memahami masalah perusahaan. 
Mc Shane dan Von Glinow $(2010 ; 187)$ bahwa "empowerment is a psychological concept represented by four dimensions: self-determination, meaning, competence, and impact regarding the individual's role in the organization". Pemberdayaan merupakan konsep psikologis yang diwakili oleh empat dimensi: menentukan nasib sendiri, pemahaman, kompetensi, dan dampak terhadap peran individu dalam organisasi.

Gary Yukl (2010: 487) menjelaskan bahwa "empowerment is more complex for teams than for dyads, and it usually means allowing the members of a team to make important task decisions collectively. Empowerment may include member influence over selection of an internal leader, the selection of new members, decisions about work procedures, the assignment of tasks to members, and evaluation of each members performance". Pemberdayaan lebih kompleks untuk tim sehingga memungkinkan anggota tim untuk membuat keputusan kolektif yang berkaitan dengan tugas penting. Pemberdayaan mungkin termasuk pengaruh anggota selama pemilihan pemimpin internal, pemilihan anggota baru, keputusan tentang prosedur kerja, tugas-tugas kepada anggota, dan evaluasi kinerja masingmasing anggota. Lebih lanjut pemberdayaan merupakan pemberian tanggung jawab dan wewenang terhadap pekerjaan untuk mengambil keputusan menyangkut semua pengembangan produk dan pengambilan keputusan.

Menurut Richard L. Daft (2008: 243) bahwa "empowerment is power sharing: the delegation of power or authority to subordinates in the organization". Pemberdayaan erat kaitannya dengan pembagian kekuasaan, pelimpahan kekuasaan atau wewenang kepada bawahan dalam organisasi sehingga dapat mendorong orang untuk lebih terlibat dalam pembuatan keputusan dalam organisasi. Selain itu, pemberdayaan pegawai tersebut berupaya untuk mendorong pegawai memegang tanggung jawab melalui perbaikan cara bekerja dalam pencapaian tujuan organisasi.

Menurut Griffin Moorhead (2007:127) bahwa "empowerment is the process of enabling workers to set their own work goals, make decisions, and solve problems within their sphere of responsibility and authority". Adanya proses yang memungkinkan pekerja untuk menetapkan tujuan kerja mereka sendiri, membuat keputusan, dan memecahkan masalah dalam lingkup tanggung jawab dan wewenang.

James L. Gibson ((2012: 508) et. al juga menjelaskan bahwa "empowerment individuals means granting them permission to use their talents, skills, resources and experience to make decisions about custemer relationship management, investments, hiring people, just-intime inventory management, total quality control, computer purchases, and forming alliances. Pemberdayaan berarti memberikan mereka izin untuk menggunakan bakat mereka, keterampilan, sumber daya dan pengalaman untuk membuat keputusan tentang manajemen sehingga pemberdayaan pegawai ini dapat mendorong dan memungkinkan individu-individu untuk mengemban tanggung jawab pribadi atas upaya mereka memperbaiki cara mereka melaksanakan pekerjaan-pekerjaan mereka dan menyumbang pada pencapaian tujuan-tujuan organisasi. Seorang pegawai memiliki wewenang dan berinisiatif untuk melakukan sesuatu yang dipandang perlu, jauh melebihi tugasnya sehari hari.

Dari beberapa deskripsi konsep di atas maka dapat disintesiskan bahwa pemberdayaan adalah upaya untuk mendorong pegawai memegang tanggung jawab melalui perbaikan cara bekerja dalam pencapaian tujuan dalam bentuk keterlibatan dalam pengambilan keputusan, pengembangan kompetensi, pemberian tanggung jawab, dan pemberian wewenang. 


\section{Metode}

Penelitian ini menggunakan pendekatan kualitatif dengan metode studi kasus. Penggunaan pendekatan dan metode ini disesuaikan dengan tujuan penelitian yaitu untuk memperoleh pemahaman yang mendalam tentang bentuk supervisi dalam pelatihan di SD Islam Al-Azhar 20 Cibubur dengan memanfaatkan beberapa sumber bukti.

Metode studi kasus dengan pendekatan kualitatif merupakan sebuah investigasi secara bertahap. Peneliti berusaha memahami fenomena yang terjadi dengan membedakan, membandingkan dan mengelompokkan objek penelitian. Peneliti memasuki dunia responden dan melakukan interaksi terus menerus, kemudian mencari sudut pandangnya. Dalam penelitian ini, investigasi yang dilakukan adalah untuk mencari data dan informasi mengenai supervise dalam pelatihan, yang berfokus pada proses pelatihan guru, peran Kepala Sekolah dalam melakukan supervisi dan bentuk pemberdayaan guru yang dihasilkan. Penelitian ini menekankan pada proses dalam mencapai tujuan yang telah ditetapkan.

\section{Temuan dan Pembahasan Hasil Penelitian}

\section{Proses Pelatihan}

\section{a. Temuan}

Kepala Sekolah berpendapat bahwa "training" adalah suatu investasi karena semakin profesional seorang guru maka mutu pendidikan akan lebih baik. Selain itu perlu diingat bahwa guru yang tidak pernah melakukan pelatihan dalam kurung waktu dua tahun maka guru tersebut akan cenderung mengulang metode pengajaran yang sama.

Guru kami wajibkan mengikuti pelatihan minimal 100 jam dalam setahun. Dan terakhir pada tataran pelaksanaan nara sumber benar-benar akan melatih guru untuk pengembangan kemampaun mengajar. Menurut kepala sekolah bahwa guru yang tidak pernah melakukan pelatihan dalam kurun waktu dua tahun maka guru tersebut akan cenderung mengulan-ulang metode pengajaran yang sama. Guru kami wajibkan mengikuti pelatihan manimal 100 jam dalam setahun.

\section{b. Analisis}

Proses pelatihan yang dilaksanakan oleh SD Islam Al Azhar 20 Cibubur berdasarkan data yang diperoleh oleh peneliti setelah mengadakan wawancara jika dihubungkan dengan teori-teori tentang pelatihan saling mempunyai relevansi seperti pada pernyataan kepala sekolah bahwa "training" merupakan investasi sekolah karena semakin profesional guru yang dimiliki sekolah maka semakin bagus mutu sekolah tersebut. Hal tersebut sesuai dengan teori dalam buku Modern Labor Economic Theory and public Policy, dalam buku tersebut S. Smith dan Greenberg (2009:115) berpendapat bahwa "we have identified employer-provided training as an important investment. (kami menemukan bahwa penyediaan pelatihan untuk pegawai merupakan investasi yang sangat penting.

Pelatihan merupakan investasi besar dari lembaga karena kemampuan karyawan dalam melakukan pekerjaanya akan berdampak langsung pada mutu yang dihasilkan oleh institusi tersebut. Jika mutu bagus maka dengan secara langsung menjaga konsumen untuk tetap memakai produk atau jasa perusahaan 
tersebut, jika berhubungan dengan institusi sekolah profesionalisme guru akan menghasilkan lulusan sekolah yang berkualitas.

\section{Proses Supervisi dalam pelatihan guru}

a. Temuan

Proses supervisi melalui beberapa tahapan yang disusun berdasarkan kebutuhan supervisi. Proses supervisi melalui tahapan, yaitu membuat jadwal, supervisi kemudian menetapkan instrumen yang akan disupervisi seperti alat pendukung pembelajaran dan RPP. Setelah supervisi guru diberikan masukan kemudian hasil supervisi dilaporkan kepada kepala sekolah. Hasil supervisi tersebut akan memberikan masukan kepada kepala sekolah untuk melakukan tindakan selanjutnya.

Pada pelaksanaan supervisi secara umum dilakukan dengan penjadwalan di awal Tahun Ajaran, namun untuk supervisi terhadap pelatihan dilakukan setelah materi pelatihan selesai oleh narasumber, namun ada supervisi internal yang dilakukan oleh kepala sekolah untuk melihat sejauh mana pemberian materi kepada guru dalam pelatihan.

\section{b. Analisis}

Guru-guru dan kepala sekolah perlu terus-menerus berpikir untuk mencari variasi langkah kegiatan dalam supervisi agar memperoleh data yang lebih baik dan model pembinaan yang lebih baik dan model pembinaan yang lebih efektif.

Maka untuk meningkatkan kualitas pengajaran kepala sekolah melakukan inovasi dalam supervisi yang rumusanya mengadopsi supervisi klinis dengan langkah-langkah sebagai berikut: Kepala sekolah sebagai pembina berdiskusi untuk menyusun penjadwalan pelaksanaan supervisi, supaya pelaksanaan supervisi tidak simpang siur. Kemudian Kepala sekolah menelaah instrumen yang diperlukan dalam supervisi. Setelah jadwal supervise lalu dikoordinasikan kepada semua guru, supervisi cenderung tidak terlalu kaku guru ditawarkan untuk memilih jadwal untuk disupervisi. Kepala sekolah memberikan masukan kepada guru. Langkah-langkah tersebut di atas merupakan langkah-langkah supervisi secara umum. Herabudin mengatakan bahwa langkah-langkah supervisi yang bersifat umum adalah menilai dan mengarahkan tujuan instruksional yang dirumuskan guru, garis pokok bahasan, media pengajaran yang dipergunakan, tugas dan tes yang diberikan dan jadwal pelajaran yang dipatuhi. ${ }^{1}$

Ditinjau dari Pelaksanaan Supervisi maka proses supervisi menurut Ngalim Purwanto adalah supervisi koreaktif, supervisi preventif, supervisi konstruktif, supervisi kreatif dan supervisi kooperatif. ${ }^{2}$ Berdasarkan pengamatan dan hasil wawancara maka peneliti menemukan bahwa supervisi yang dilakukan di SD Islam Al-Azhar 20 Cibubur adalah Supervisi Konstruktif supervisi kreatif dan supervisi kooperatif.

\footnotetext{
${ }^{1}$ Herabudin, Administrasi dan Supervisi Pendidikan, ( Pustaka Setia; Bandung, 2009), h. 232

2 Ngalim Purwanto op cit, h. h.105
} 
Supervisi konstruktif adalah supervisi yang membantu guru untuk belajar dari kesalahan dan tidak mengulangi kesalahan tersebut. Selain melakukan supervisi konstruktif juga ada pelaksanaan Supervisi Kreatif tergantung akan kebutuhan guru yang disupervisi, setiap guru mendapatkan porsi supervisi sesuai dengan kebutuhan guru tersebut. Supervisor menciptakan situasi yang dapat meningkatkan kreatifitas guru.

Berdasarkan penjelasan informan peneliti mendapat kesimpulan bahwa SD Islam Al-Azhar 20 Cibubur melaksanakan supervisi kooperatif. Dengan melibatkan narasumber sebagai supervisor di kelas-kelas merupakan bentuk supervisi kooperatif yang dilakukan oleh sekolah SD Islam Al-Azhar 20 Cibubur dalam rangka peningkatan mutu pendidikan

\section{Kepala Sekolah sebagai Supervisor}

a. Temuan

Kepala sekolah menyusun program supervisi kemudian melaksanakannya. seperti memberikan pembinaan, penilaian dan bantuan atau bimbingan mulai dari rencana program proses sampai dengan hasil. Mensupervisi guru dalam meningkatkan kualitas proses pembelajaran dan kualitas hasil belajar siswa. Untuk supervisi secara umum kepala sekolah menyusun program program kerja pengawasan, memberikan penilaian menganalisa data hasil belajar, memberikan saran arahan kepada guru tentang proses pembelajaran dan lain-lain. Khusus untuk pelatihan supervisi diadakan oleh narasumber, dengan criteria pengawasan ditentukan oleh mereka. Hasil supervisi tersebut akan ditindak lanjuti oleh kepala sekolah. Mengadakan supervisi pada proses belajar mengajar, kegiatan kerjasama dengan instansi lain, kegiatan konseling, sarana dan prasarana sekolah. Memberikan pengawasan penuh dalam semua kegiatan sekolah.

Selain itu, supervisi kepala sekolah memberikan wewenang kepada wakil kepala sekolah jika kepala sekolah sedang berhalangan. Ada juga guru senior. tergantung apa yang yang kan disupervisi. Namun dalam pelatihan kepala sekolah mempunyai kebijakan tersendiri yaitu mendelegasikan wewenang kepada nara sumber. Hal tersebut mengingat nara sumberlah yang paling berkompetensi menilai kemampuan guru. Nara sumber tersebut melakukan supervisi dan memastikan apa yang telah dipelajari dalam pelatihan dilaksanakan dalam kelas yang sebenarnya. Misalnya supervisi pelatihan bahasa Inggris, maka yang masuk ke kelas-kelas adalah pihak narasumber untuk melihat perkembangan sesudah mengikuti pelatihan. Dan pelatihan TKT maka supervisi dari Cambrige yang melalukan supervisi kepada guru-guru. hasil seupervisi tersebut kemudian akan ditindaklanjuti oleh kepala sekolah

\section{b. Analisis}

Kepala sekolah sebagai penanggung jawab segala kegiatan dalam sekolah mempunyai tugas-tugas pokok yang harus dilaksanakan. Hal yang diungkapkan oleh responden kami jika dihubungkan dengan fungsi-fungsi pokok manajer dalam hal ini kepala sekolah menurut Ngalim Purwanto (2010:6) adalah planning, organizing, actuating/staffing, commanding/directing, coordinating, controlling/supervision, communicating dan sebagainya juga merupakan fungsi-fungsi pokok administrasi. 
Menurut pengamatan peneliti, supervisi yang yang melibatkan orang luar merupakan bentuk supervisi artistik. Supervisi itu menyangkut bekerja untuk orang lain (working for the others), bekerja dengan orang lain (working with the others), bekerja melalui orang lain (working through the others). Dalam hubungan bekerja dengan orang lain maka suatu rantai hubungan kemanusiaan adalah unsur utama. Hubungan manusia dapat tercipta bila kerelaan untuk menerima orang lain sebagaimana adanya.

Menurut Thomas Gordon yang dikutip dalam bukunya Piet A. Sahertian (2011:157) mengatakan Supervisi lebih banyak menggunakan bahasa penerimaan ketimbang bahasa penolakan. Supervisor yang mengembangkan model artistik akan menampakkan dirinya dalam relasi dengan guru-guru yang dibimbing sedemikian baiknya sehingga para guru merasa diterima. Adanya perasaan aman dan dorongan positif untuk berusaha terus maju. Sikap seperti mau belajar mendengarkan perasaan orang lain, mengerti orang lain dengan problem-problem yang dikemukakan, menerima orang lain sebagaimana adanya, sehingga orang dapat menjadi dirinya sendiri, itulah supervisi artistik.

Lebih lanjut, menurut Ivancevich dan Donnelly yang dikutip oleh Mukhneri Mukhtar (2011:22) bahwa “organization that decentralize (delegate) autorithy enable managers to make significant decision to gain skill and advance in the company". Ini menjelaskan bahwa manajer yang bisa mendelegasikan wewenang akan mampu membuat keputusan penting untuk kemajuan lembaganya (sekolah).

\section{Pemberdayaan guru a.Temuan}

Menurut koordinator pelatihan, guru diberikan stimulus berupa kenaikan golongan, guru terbaik akan difasilitasi oleh sekolah untuk mengikuti tes sertifikasi mengajar standar internasional yaitu Teaching Knowledge Test. Selain itu, juga untuk memotivasi guru dimana peningkatan jenjang karir sangat terbuka luas, Peningkatan Golongan naik tanpa menunggu waktu lama tetapi sesuai dengan prestasi masing-masing.

\section{b. Analisis}

Menurut analisis peneliti, suatu program akan berjalan jika ada stimulus, menurut para ahli bahwa dari eksperimen yang dilakukan Thorndike (2009:33) terhadap kucing menghasilkan hukum-hukum belajar, diantaranya: Law of Effect; artinya bahwa jika sebuah respons menghasilkan efek yang memuaskan, maka hubungan Stimulus - Respons akan semakin kuat. Sebaliknya, semakin tidak memuaskan efek yang dicapai respons, maka semakin lemah pula hubungan yang terjadi antara Stimulus- Respons.Law of Readiness; artinya bahwa kesiapan mengacu pada asumsi bahwa kepuasan organisme itu berasal dari pendayagunaan satuan pengantar (conduction unit), dimana unit-unit ini menimbulkan kecenderungan yang mendorong organisme untuk berbuat atau tidak berbuat sesuatu. Law of Exercise; artinya bahwa hubungan antara Stimulus dengan Respons akan semakin bertambah erat, jika sering dilatih dan akan semakin berkurang apabila jarang atau tidak dilatih 


\section{PENUTUP}

Kesimpulan: Pelatihan yang disupervisi merupakan salah satu cara yang dilakukan oleh SD Islam Al-Azhar 20 Cibubur untuk meningkatkan sumber daya guru yang berdampak langsung pada peningkatan mutu sekolah. Pelatihan yang disupervisi melibatkan narasumber merupakan bentuk supervisi yang tergolong unik, narasumber pelatihan tidak hanya melatih guru untuk memahami sebuah metode pelatihan namun juga akan diberikan pengawasan ketika berada dalam kelas yang sesungguhnya. Pengawasan tersebut masih merupakan bagian dari pelatihan, Supervisi dimaksudkan untuk memberikan masukan kepada guru. Pelatihan yang disupervisi tersebut adalah salah satu bentuk pemberdayaan guru. Pemberdayaan dianggap efektif jika dibarengi dengan peningkatan kualitas para guru.

Rekomendasi: Berdasarkan kesimpulan di atas, maka peneliti mengajukan beberapa rekomendasi antara lain: (1) pelatihan harus diadakan secara berkesinambungan dan terfokus. (2) evaluasi tidak hanya befokus pada guru namun juga memperhatikan kenyamanan peserta didik. (3) pemberdayaan tidak hanya memberikan kesempatan kepada guru yang berprestasi namun membimbing guru dengan kemampuan standar untuk tetap berdaya. 


\section{DAFTAR RUJUKAN}

Dadang Suhardan et. al, Manajemen Pendidikan, Alfabeta; Bandung, 2009.

Faustino Cardoso Gomes. Manajemen Sumber Daya Manusia, Yogyakarta: Andi Offset 2003.

Mukhneri Mukhtar, Supervision Improving Performance and Development Quality in Education. PPs UNJ PRESS; Jakarta, 2011.

Mukhtar, Iskandar, Orientasi Baru Supervisi Pendidikan. GP Press; Jakarta, 2009.

Mulyasa E. Standar Kompetensi dan sertifikasi Guru. Bandung: Remaja Rosdakarya, 2009.

Mulyasa. Standar Kompetensi dan Sertifikasi Guru. PT. Remaja Rosdakarya: Bandung, 2009.

Russell, Taylor, Operating Management Focusing on Quality and Competitiveness, 2003.

Sudarwan Danim, Suparno, Manajemen dan Kepemimpinan Transformasional Kepala Sekolah. PT, Rineka Cipta : Jakarta, 2009.

Sufyarma, Kapita Selekta Manajemen Pendidikan, Alfabeta: Jakarta, 2003.

Werther, JR, William B, Keith Davis, Managing personality, USA: McGraw-Hill book, 1993. 
